\title{
OZONE EFFECT ON THE PROPERTIES OF ARAMID FABRIC
}

\author{
Yan Wang, Jakub Wiener, Jiri Militky, Rajesh Mishra, Guocheng Zhu
}

Department of Textile Material Engineering, Technical University of Liberec, Liberec, Czech Republic, Studentská 1402/2, Tel: +420 774846310, E-mail: zgc100100@hotmail.com

\begin{abstract}
:
The limitation of aramid fiber is its surface property, which results in its very poor interfacial adhesion to most of commercial resins. In order to improve the surface property of the aramid fiber, ozone treatment was carried out in this work. The aramid fabrics were evaluated in terms of surface morphology, wicking effect, tensile property, and ball bursting test. The results showed that the surface morphology of aramid fabrics did not undergo an obvious change; the wicking effect increased slightly with an increase in ozone treatment time; the tenacity and elongation of aramid fibers and fabrics did not significant change after ozone treatment, but the tenacity and elongation of aramid yarns showed significant improvement after ozone treatment, and increased with the increase of ozone treatment time; the ball bursting load and penetration displacement had a slight increase as well after ozone treatment. Therefore, ozone treatment could be one method to improve the surface property of the aramid fiber.
\end{abstract}

\section{Keywords:}

Ozone treatment; Aramid fabric; Wicking effect; Mechanical properties

\section{Introduction}

Aramid fibers have found applications in protective products, which mostly are ballistic proof, fireman clothes, and reinforcement for high-performance composites due to its high specific modulus and strength with excellent thermal stability, high melting point, excellent flame resistance with low levels of smoke generation, chemical inertness, and comfort [1, 2]. However, the utilization of aramid fiber as reinforcement has been limited by the poor fiber-matrix interfacial adhesion due to the fiber's smooth surface and its inert chemical structure, which provides very low bonding strength with most of the commercially available resins used in composites [3-5].

In order to solve the above issue, a number of researches have been focusing on the improvement of fiber's surface properties by various surface treatment techniques, such as chemical treatment (using coupling agents and chemically grafting methods), plasma treatment, corona discharge, irradiation with gamma-rays, ozonation, etc. [6-10]. Among these techniques, ozonation has the advantage of uniformly introducing peroxides on the polymer surfaces even with complex shapes. The generated peroxides are capable of initiating radical graft polymerization of hydrophilic vinyl monomers onto the polymers, resulting in hydrophilic surfaces [11]. The ozonation process removes impurities from the surface and introduces oxygen-containing functional groups, which aid in adhesion to the matrix. Moreover, ozonation is an easy-to-handle and inexpensive method [12].

Most researchers $[5,8,13]$ investigated the surface property by evaluating the surface chemical functional groups or roughness. However, the biggest advantage of aramid fiber as a high-performance fiber is its high strength. Therefore, it is also important to evaluate the strength of aramid fiber before and after surface modification.

In this study, aramid fibers were treated by ozone at different time durations, and its fabrics were evaluated in terms of surface morphology, wicking property, tensile property, and ball-bursting property.

\section{Materials and Methods}

\subsection{Materials and preparation}

\subsubsection{Aramid fabrics and chemicals}

Commercial grade $5 / 3$ warp-face satin aramid fabrics with an areal density of $340 \mathrm{~g} / \mathrm{m}^{2}$ were used. These fabrics were made of 2000D untwisted single yarns in warp and weft, having $68 \times 68$ ends $/ 10 \mathrm{~cm}$, and $0.7 \mathrm{~mm}$ in thickness.

Fabrics were cut into the same size and dipped in laboratory grade acetone for two hours, and then dried over 10 minutes in ventilator.

\subsubsection{Apparatus and procedure of ozone treatment}

Ozone treatment of the aramid fabrics was carried out in gaseous phase. The apparatus and the procedure of ozone treatment are described in the following.

The ozone treatment system is described diagrammatically in Figure 1. Ozone was generated from air. Before air entered the ozone generator where ozone generated, it went through an exsiccator. Then, the generated ozone was sent to the reactor 
where the surface modification of aramid fabrics occurred, and the concentration of ozone was measured by a flow meter. The applied ozone dose can be readily adjusted by controlling the ozone weight percentage and/or the gas flow rate. The ozone weight percentage in this study was fixed at $1.7 \mathrm{mg} / \mathrm{L}$ while keeping the gas flow at a rate of $2 \mathrm{~L} / \mathrm{min}$ and the pressure constant. The reactor was a plexiglass cylindrical column with a volume of $100 \mathrm{~mL}$, and fabrics were wrapped and fixed inside the reactor. Excessive ozone releasing from the reactor was destroyed by an ozone destructor.

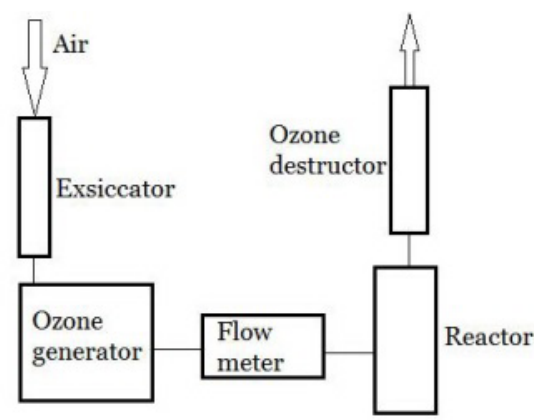

Figure 1. Schematic diagram of ozone treatment system

The ozone treatment process started when the ozone-air mixture from the ozone generator was led into the reactor. The reactor was operated by feeding the ozone-containing gas continuously. All ozonation runs were conducted around $22^{\circ} \mathrm{C}$. Fabrics were taken out from the reactor at different time intervals and were degassed under ventilator for several hours for removal of the absorbed ozone. The time intervals of ozone treatment were: $5,10,15$, and 30 minutes.

\subsection{Characterization methods}

\subsubsection{Scanning electron microscopy}

The surfaces of samples were examined by scanning electron microscopy (SEM). Before observing the samples in the SEM, specimens were sputter-coated with a thin layer of gold by electro deposition to make the surfaces conductive and reduce charging.

\subsubsection{Wicking test}

The fabric size for wicking test was $1 \mathrm{~cm} \times 15 \mathrm{~cm}$ in width and in length, the temperature of water was $25^{\circ} \mathrm{C}$, and the immersion depth of fabric into water was $0.5 \mathrm{~cm}$. The wicking property was measured by recording the time duration in a certain distance covered by liquid.

The distance covered by a liquid flow under capillary pressure in horizontal capillaries is given by the Washburn-Lucas equation $[14,15]$.

$$
l^{2}=\frac{R_{D}^{2} \gamma \cos \theta}{R_{s} 2 \eta} \cdot t
$$

$$
\text { Or } l^{2}=A \cdot t
$$

where $A=\left(R_{D}^{2} \gamma \cos \theta\right) /\left(R_{s} 2 \eta\right)$ is taken as wicking coefficient, which indicates the wicking height square is proportional to time. $R_{D}$ is the mean hydrodynamic radiuss of pores, $\eta$ is the viscosity of the liquid, $y$ and $\rho$ are the surface tension and density of the liquid, $\theta$ is the advancing contact angle of the liquid on the solid, $R_{S}$ is the mean static radius of the pores, and $t$ is time.

\subsubsection{Tensile testing}

Testomatric tester was used for evaluating the tensile property of aramid fabrics. The dimensions of fabrics were $1 \mathrm{~cm}$ in width and $15 \mathrm{~cm}$ in length. The gauge length for testing was $100 \mathrm{~mm}$ and the moving head of testomatric tester was at a speed of $100 \mathrm{~mm} / \mathrm{min}$. The tensile strength of weft yarns from aramid fabric was measured by Instron model 4411 tester at $100 \mathrm{~mm}$ gauge length and at a speed of $100 \mathrm{~mm} / \mathrm{min}$ of the moving head. Each group of sample was measured five times, the average value, and the standard deviation were determined.

The linear density of the fiber was measured by LENZING VIBROSKOP 400 , and tensile property of aramid fibers was evaluated by LENZING VIBRODYN 400 at $10 \mathrm{~mm}$ gauge length and at a speed of $10 \mathrm{~mm} / \mathrm{min}$ of moving head under $200 \mathrm{mg}$ preload. All samples were tested keeping them in a conditioned lab environment for 24 hours. Each group of sample was tested 100 times.

\subsubsection{Ball bursting test}

A Testomeric tester M350-10CT was used to evaluate the bursting strength of aramid fabrics. In the test, the aramid fabric sample was fixed in the testing area, and then a $25 \mathrm{~mm}$ diameter steel ball was pushed through the sample at a speed of $500 \mathrm{~mm} / \mathrm{min}$.

\section{Results and Discussion}

\subsection{Surface morphology}

The surface SEM images of aramid fabrics under ozone treatment at different time intervals are given in Figure 2. The untreated aramid fabric had a very smooth surface (Fig. 2 A, $0 \mathrm{~min}$ ), and the treated samples were found to have some damages and irregular spots on the fiber surface (Fig. 2B-E). The spots increased slightly with an increase in the ozone treatment time. The damages and the spots may be due to the reaction between ozone and aramid molecules or other micro molecules on the surface of the fibers.

\subsection{Wicking property}

The wicking property of aramid fabrics with different ozone treatment time are given in Figure 3A. According to Equation (2), the square of the wicking height is proportional to time. Therefore, the correlation between square of the wicking 
A

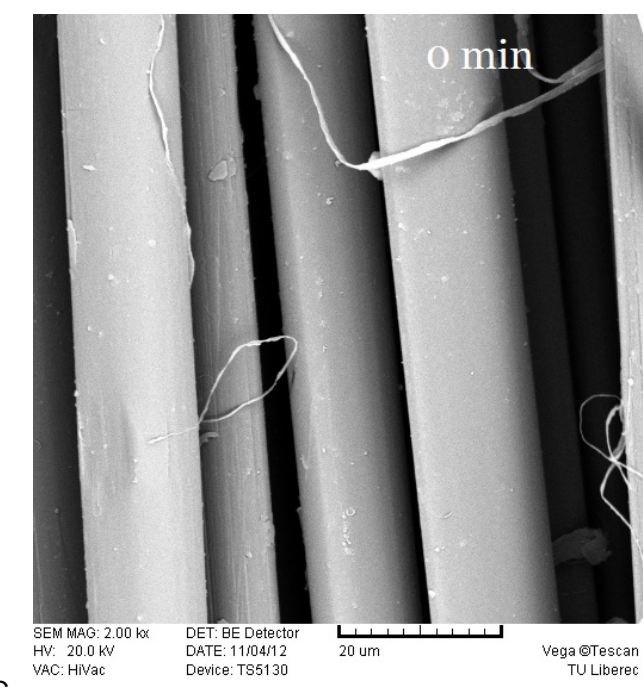

C

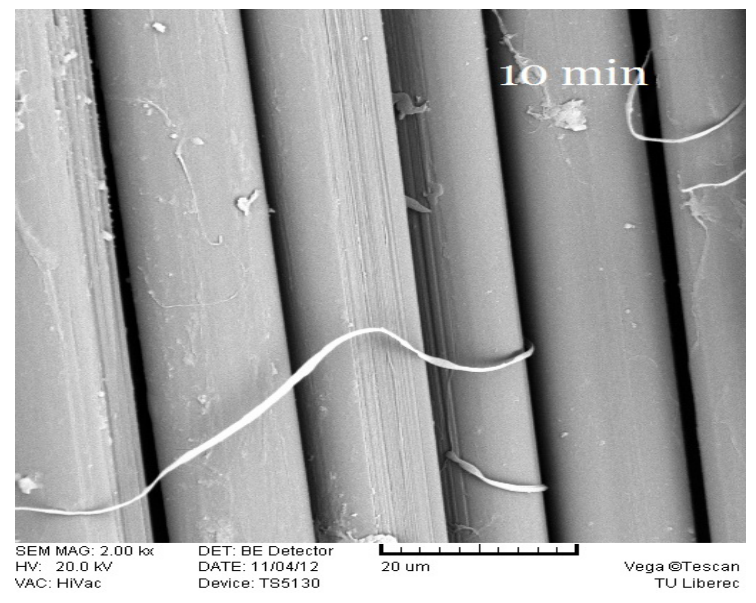

$\mathrm{E}$

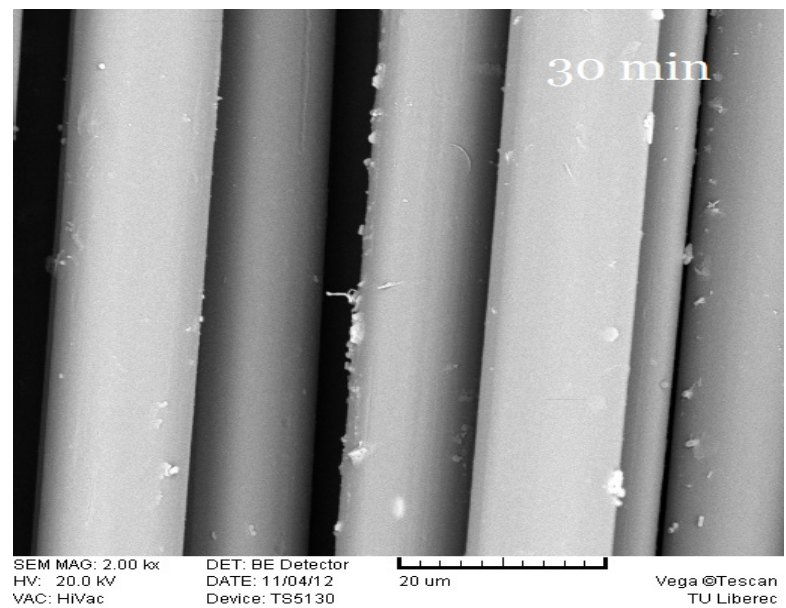

B

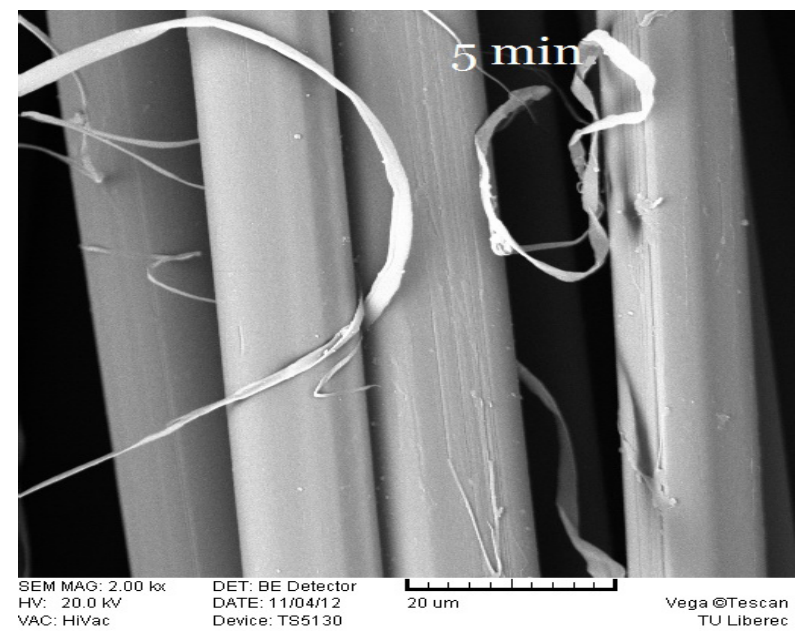

D

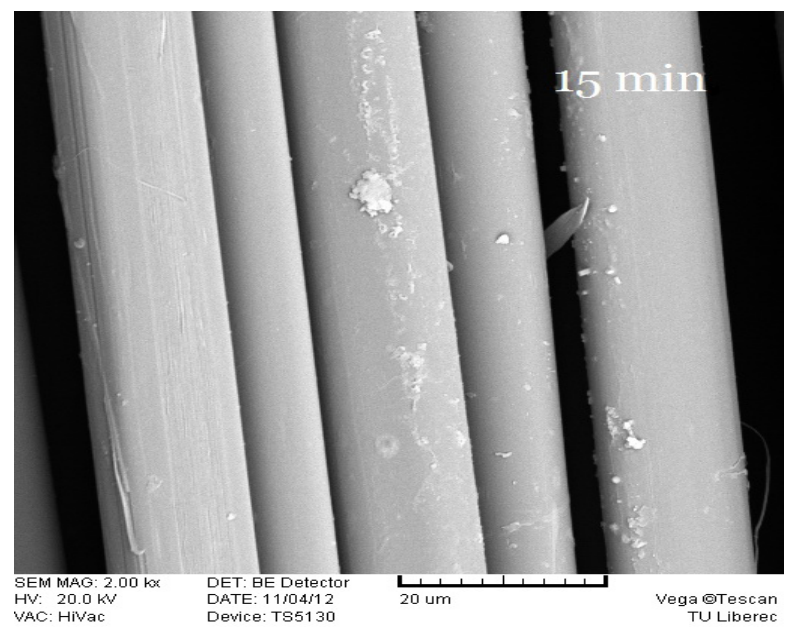

Figure 2. SEM images of aramid fabrics before and after ozone treatment

height and time is given in Figure 3B. The slope of linear fitting represents the wicking coefficient. The bigger the wicking coefficient is, the shorter the wicking time will be. The results revealed that the wicking rate becomes faster and the wicking property was improved.

The wicking coefficients of aramid fabrics at different time intervals of ozone treatment are given in Table 1, in which the results showed that the wicking property improved with the increase of ozone treatment time.

\subsection{Tensile property}

\subsubsection{Tensile property of aramid fibers}

The tensile properties of fibers at different ozone treatment times are given in Table 2 . The tenacity and elongation of fibers had insignificant difference, which indicated that the ozone treatment did not have an impact on the tensile property of aramid fibers. 

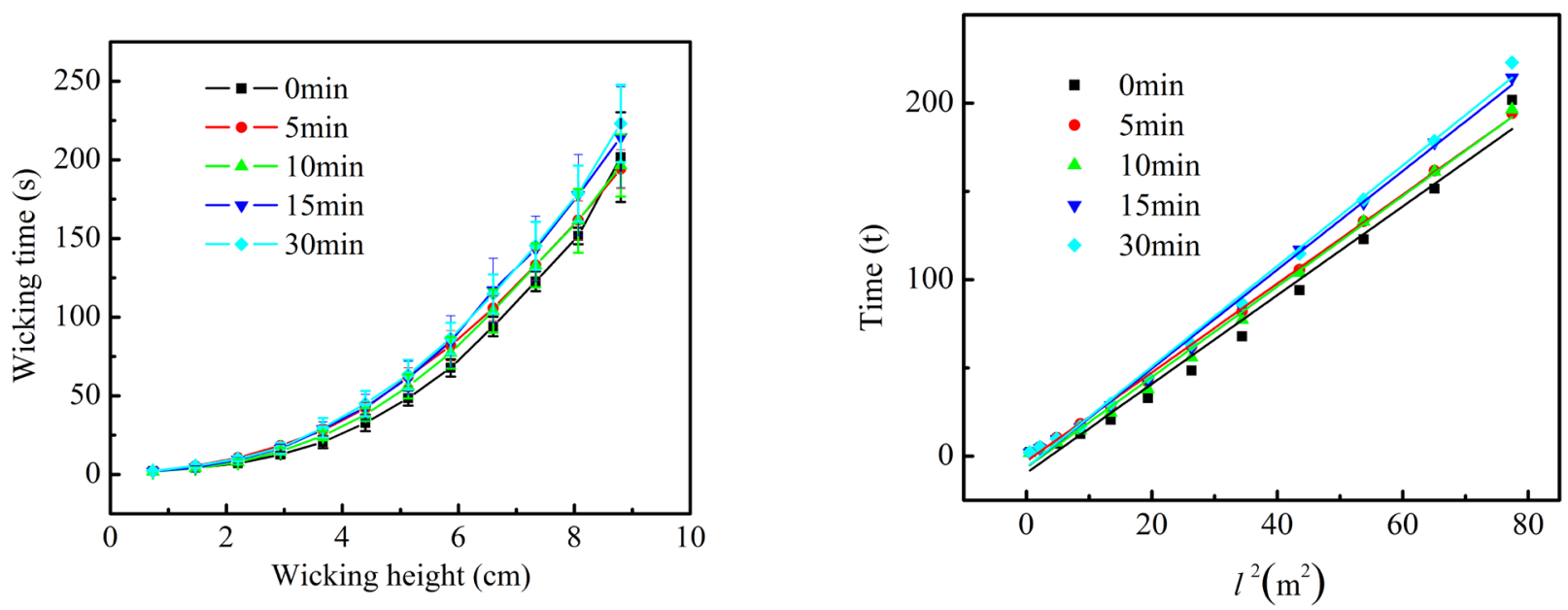

Figure 3. Wicking property of fabrics at different time intervals of ozone treatment.

\subsubsection{Tensile property of yarns}

The tensile properties of yarns at different ozone treatment times are given in Table 3 . The tensile strength of yarns increased with the increase of ozone treatment time, especially when the duration of the ozone treatment was 30 minutes, the tenacity of yarn increased by $25.84 \%$. However, the elongation of yarn decreased with an increase in the ozone treatment time. This improvement of strength may be due to the friction effect between single fibers after the ozone treatment.

\subsubsection{Tensile property of fabrics}

Tensile properties of fabrics in both warp and weft directions were tested. Fig. 4 shows the tensile curves of the fabric in the weft direction. Similar tensile results were found in the warp

Table 1. Wicking coefficients of aramid fabrics at different ozone treatment times

\begin{tabular}{|c|c|c|}
\hline $\begin{array}{c}\text { Exposed time } \\
(\mathbf{m i n})\end{array}$ & Wicking coefficient & \multicolumn{2}{|c|}{$\begin{array}{c}\text { The correlation coefficient } \\
\mathbf{R}^{\mathbf{2}}\end{array}$} \\
\hline 0 & $2.51 \pm 0.06$ & 0.983 \\
\hline 5 & $2.52 \pm 0.03$ & 0.995 \\
\hline 10 & $2.56 \pm 0.03$ & 0.996 \\
\hline 15 & $2.80 \pm 0.03$ & 0.998 \\
\hline 30 & $2.85 \pm 0.04$ & 0.996 \\
\hline
\end{tabular}

Table 2. Tensile properties of fibers at different ozone treatment time

\begin{tabular}{|c|c|c|c|c|}
\hline $\begin{array}{c}\text { Exposed Time } \\
(\mathbf{m i n})\end{array}$ & Tenacity (cN/tex) & $\begin{array}{c}\text { Increase by } \\
\text { percentage (\%) }\end{array}$ & Elongation (\%) & $\begin{array}{c}\text { Increase by } \\
\text { percentage (\%) }\end{array}$ \\
\hline 0 & $222.03 \pm 22.07$ & 0 & $3.62 \pm 0.39$ & 0 \\
\hline 5 & $225.36 \pm 18.85$ & 1.5 & $3.62 \pm 0.32$ & 0 \\
\hline 10 & $218.83 \pm 19.01$ & -3.2 & $3.48 \pm 0.29$ & -3.87 \\
\hline 15 & $217.44 \pm 20.62$ & -2.1 & $3.48 \pm 0.36$ & -3.87 \\
\hline 30 & $221.75 \pm 26.02$ & -0.1 & $3.65 \pm 0.41$ & 0.8 \\
\hline
\end{tabular}

Table 3. Tensile properties of yarns at different ozone treatment time

\begin{tabular}{|c|c|c|c|c|}
\hline $\begin{array}{c}\text { Exposed Time } \\
\text { (min) }\end{array}$ & $\begin{array}{c}\text { Tenacity } \\
\text { (cN/tex) }\end{array}$ & $\begin{array}{c}\text { Increase by } \\
\text { percentage (\%) }\end{array}$ & $\begin{array}{c}\text { Elongation } \\
\text { (\%) }\end{array}$ & $\begin{array}{c}\text { Increase by } \\
\text { percentage (\%) }\end{array}$ \\
\hline 0 & $81.15 \pm 7.11$ & 0 & $5.5 \pm 2.2$ & 0 \\
\hline 5 & $93.09 \pm 5.86$ & 14.71 & $4.6 \pm 2$ & -16.36 \\
\hline 10 & $95.91 \pm 3.09$ & 18.19 & $4.8 \pm 1.9$ & -12.73 \\
\hline 15 & $97.49 \pm 3.87$ & 20.13 & $4.99 \pm 1.8$ & -9.27 \\
\hline 30 & $102.12 \pm 4.19$ & 25.84 & $3.88 \pm 1.1$ & -29.45 \\
\hline
\end{tabular}


Table 4. Tensile properties of aramid fabric on warp direction under different ozone exposed times

\begin{tabular}{|c|c|c|c|c|}
\hline $\begin{array}{c}\text { Exposed Time } \\
(\mathbf{m i n})\end{array}$ & $\begin{array}{c}\text { Maximum strength } \\
\mathbf{( N )}\end{array}$ & $\begin{array}{c}\text { Increase by } \\
\text { percentage (\%) }\end{array}$ & $\begin{array}{c}\text { Elongation } \\
\text { (\%) }\end{array}$ & $\begin{array}{c}\text { Increase by } \\
\text { percentage (\%) }\end{array}$ \\
\hline 0 & $1791.8 \pm 80.5$ & 0 & 7.309 & 0 \\
\hline 5 & $1746.4 \pm 50.3$ & -2.53 & 7.286 & -0.31 \\
\hline 10 & $1814.2 \pm 34.2$ & 1.25 & 7.758 & 6.14 \\
\hline 15 & $1721.6 \pm 70.6$ & -3.91 & 7.775 & 6.38 \\
\hline 30 & $1767.6 \pm 66.1$ & -1.35 & 7.516 & 2.83 \\
\hline
\end{tabular}

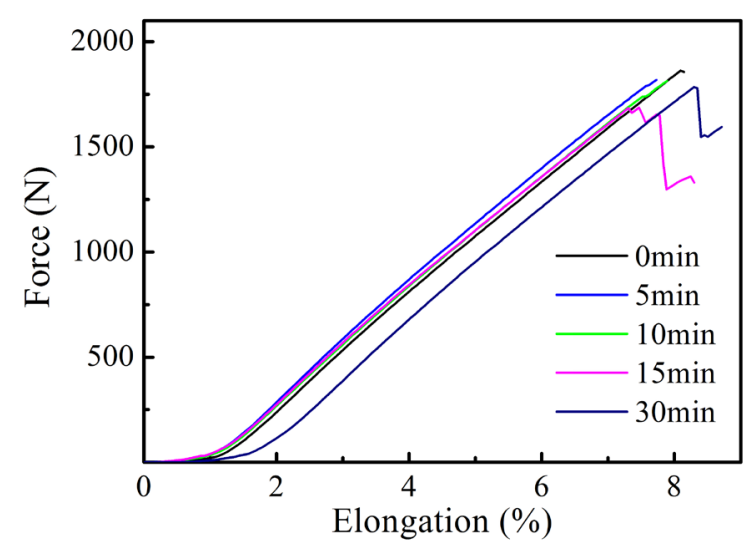

Figure 4. Tensile curves of aramid fabric in weft direction at different ozone treatment times

direction, which is given in Table 4. The tenacity and elongation of aramid fabrics did not show a significant change after ozone treatment, which also means the intensity and time of ozone treatment was not sufficient to change the mechanical property of aramid fabrics.

\subsection{Ball bursting test}

The results of aramid fabrics under ball bursting test are given in Figure 5. The maximum load and displacement of aramid fabrics increased with an increase in the ozone treatment time.

\section{Conclusions}

The ozone treatment is an easy method for fabric surface modification. Based on the experimental results, some conclusions can be drawn: (1) the surface morphology of aramid fabrics underwent a slight damage due to the reaction on the fiber surface; (2) the hydrophilic property of aramid fabrics improved with the increase of ozone treatment time, which proved that the ozone treatment had impact on the surface of the aramid fabric; and (3) the differences between tensile properties of aramid fibers and fabrics before and after ozone treatment were insignificant. But surprisingly, the tensile strength of aramid yarns showed significant improvement after ozone treatment, and the elongation had significant decrease; (4) ball bursting load and penetration displacement registered a slight increase after ozone treatment. Therefore, ozone treatment could be one effective method to modify the surface

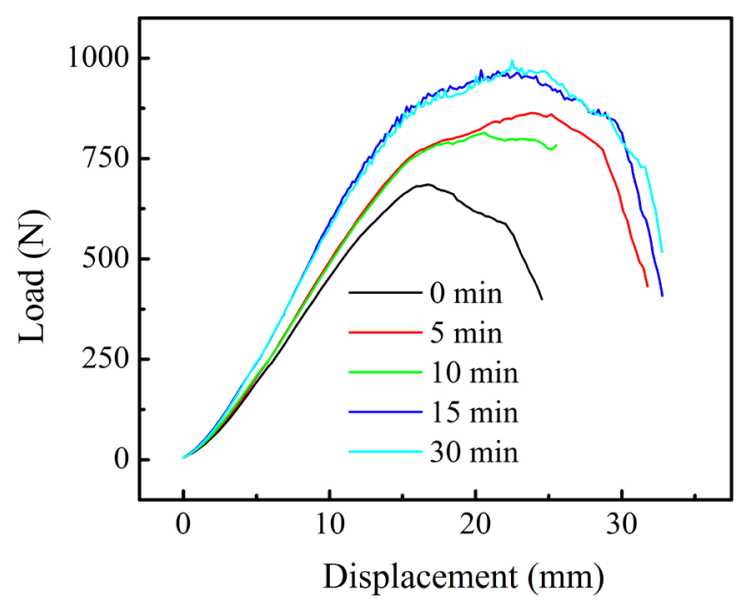

Figure 5. The load versus the displacement of aramid fabric at different ozone treatment times.

property of aramid fibers and improve the interfacial property between aramid fiber and resins.

\section{References}

[1] Bazhenov, S., (1997), Dissipation of energy by bulletproof aramid fabric. Journal of Materials Science, 32(15), 41674173.

[2] Fink, J.K., ed. (2014) High Performance Polymers. 2nd ed., William Andrew Inc.: Norwich, 301-316.

[3] Park, S.J., et al., (2002), Effect of chemical treatment of Kevlar fibers on mechanical interfacial properties of composites. Journal of Colloid and Interface Science, 252(1), 249-255.

[4] Liu, L., et al., (2008), Ultrasonic treatment of aramid fiber surface and its effect on the interface of aramid/epoxy composites. Applied Surface Science, 254(9), 2594-2599.

[5] Jia, C.X., et al., (2011), Surface treatment of aramid fiber by air dielectric barrier discharge plasma at atmospheric pressure. Applied Surface Science, 257(9), 4165-4170.

[6] Watanabe, H., et al., (2000), Surface improvements of aramid fibers by physical treatments. Macromolecular Symposia, 159, 131-141.

[7] Lin, T.K., et al., (2000), The Effect of chemical treatment on reinforcement/matrix interaction in Kevlar-fiber/ bismaleimide composites. Composites Science and Technology, 60(9), 1873-1878.

[8] Kim, E.M. and J. Jang, (2010), Surface Modification of Meta-aramid Films by UV/ozone Irradiation. Fibers and Polymers, 11(5), 677-682. 
[9] Bemska, J. and J. Szkudlarek, (2013), Surface Modification of Cotton Fabrics for Sublimation Printing. Autex Research Journal, 13(3), 67-70.

[10] Kappler, I., R.D. Hund, and C. Cherif, (2014), Surface Modification of Carbon Fibres Using Plasma Technique. Autex Research Journal, 14(1), 34-38.

[11] Patel, D., et al., (2012), Surface modification of low density polyethylene films by homogeneous catalytic ozonation. Chemical Engineering Research \& Design, 90(11), 18001806.
[12] Robin, J.J., (2004), The use of ozone in the synthesis of new polymers and the modification of polymers. New Synthetic Methods (Advances in Polymer Sci), 167, 35-79.

[13] Li, S., et al., (2014), Surface Modification of Aramid Fibers via Ammonia- Plasma Treatment. Journal of Applied Polymer Science, 131(10).

[14] Kissa, E., (1996), Wetting and wicking. Textile Research Journal, 66(10), 660-668.

[15] Washburn, E.W., (1921), The dynamics of capillary flow. Physical Review, 17(3), 273-283. 